\title{
Incursion and Spread of H5N1 Highly Pathogenic Avian Influenza Viruses among Wild Birds in 2010-11 Winter in Japan
}

\author{
Kosuke SODA $^{1)}$, Hiroshi ITO ${ }^{1,2)}$, Tatsufumi USUI ${ }^{1,3)}$, Yasuko NAGAI ${ }^{2)}$, Hiroichi OZAKI ${ }^{1,4)}$, Tsuyoshi YAMAGUCHI ${ }^{1,3)}$ \\ and Toshihiro $\mathrm{ITO}^{1,2) *}$ \\ 1) Avian Zoonosis Research Center, Faculty of Agriculture, Tottori University, 4-101 Koyama-Minami, Tottori 680-8553, Japan \\ 2) Laboratory of Veterinary Public Health, Department of Veterinary Medicine, Faculty of Agriculture, Tottori University, 4-101 Koyama- \\ Minami, Tottori 680-8553, Japan \\ 3) Laboratory of Veterinary Hygiene, Department of Veterinary Medicine, Faculty of Agriculture, Tottori University, 4-101 Koyama- \\ Minami, Tottori 680-8553, Japan \\ 4) Laboratory of Veterinary Microbiology, Department of Veterinary Medicine, Faculty of Agriculture, Tottori University, 4-101 Koyama- \\ Minami, Tottori 680-8553, Japan
}

(Received 24 November 2012/Accepted 18 December 2012/Published online in J-STAGE 28 December 2012)

ABSTRACT. Many highly pathogenic avian influenza (HPAI) outbreaks occurred in Japan during the 2010-11 winter. H5N1 HPAI viruses were isolated from 63 wild birds including migrating and resident birds, and caused HPAI outbreaks in 24 chicken farms by the end of March. In the present study, all virus strains isolated from wild birds in western Japan together with the viruses in the preceding works were phylogenetically and epidemiologically analyzed. Furthermore, the virus distributions in the raptors that died of H5N1 HPAI virus infection were assessed. The virus isolates in Japan were classified into three groups by phylogenic analysis of their hemagglutinins, supporting the previous report (Sakoda et al., 2012). The viruses in each group were continuously isolated in respective limited areas, indicating that viruses were maintained in local bird populations throughout the outbreak periods. Some viruses were genetically closely related to the Korean isolates around the same periods, suggesting that migratory birds were suspected of contributing to transportation of the viruses across the sea. Viruses were recovered from systemic tissues including digestive organs of the deceased raptors, indicating that they were infected with HPAI viruses by their predatory behavior, eating infected birds or carrion in the environment.

KEY WORDS: H5N1, influenza virus, Japan, wild bird.

doi: 10.1292/jvms.12-0512; J. Vet. Med. Sci. 75(5): 605-612, 2013

Outbreaks of highly pathogenic avian influenza (HPAI) caused by $\mathrm{H} 5 \mathrm{~N} 1$ viruses have occurred in many countries, leading to serious economic losses in the poultry industry. In addition, the H5N1 HPAI virus (HPAIV) returned to the natural host, migratory water birds, and spread to Asia, the Middle East, Europe and Africa [2, 11]. These incidents have increased the possibility of further spread of HPAIVs to humans and rare species of animals.

In Japan, the outbreaks caused by H5N1 HPAIVs occurred in chicken farms in 2003-2004 [12]. H5N1 HPAIVs were also isolated from wild birds, such as jungle crow (Corvus macrorhynchos), mountain hawk-eagle (Spizaetus nipalensis) and whooper swan (Cygnus cygnus) in 2004, 2007 and 2008 , respectively $[17,19,20]$. Furthermore, many outbreaks occurred in Japan during the 2010-11 winter. H5N1 HPAIVs were isolated from 63 wild birds including migrating and resident birds, and caused HPAI outbreaks in 24 chicken farms by the end of March $[15,21]$. These outbreaks were controlled by depopulation of chickens in the relevant farms,

\footnotetext{
*Correspondence to: Ito, T., Laboratory of Veterinary Public Health, Department of Veterinary Medicine, Faculty of Agriculture, Tottori University, 4-101, Koyama-Minami, Tottori 680-8553, Japan.

e-mail: toshiito@muses.tottori-u.ac.jp

(C)2013 The Japanese Society of Veterinary Science
}

intensive surveillance and improved biosecurity measures.

In Japan, definitive diagnoses of HPAI in poultry are given by the National Institute of Animal Health (NIAH: Tsukuba, Japan). The wild birds with suspected HPAI receive diagnostic confirmation by Hokkaido University, NIAH or Tottori University. Which institute is selected for diagnosis depends on the area where HPAI occurs. After the HPAI outbreaks in 2010-11, the three institutes published a report [15]. Thirty-three isolates were obtained and were divided into three $(\mathrm{A}-\mathrm{C})$ groups based on the phylogenetic analysis of the hemagglutinin (HA) genes [15]. The report was based on the analyses of representative virus strains. Therefore, follow-up studies were essential to elucidate the reason why the massive HPAI occurred, and to prevent outbreaks in future. In the present study, all virus strains isolated at Tottori University together with the viruses in the preceding works $[7,15,21]$ were phylogenetically and epidemiologically analyzed. Furthermore, the virus distributions in the deceased raptors were examined to evaluate their potential to be sources of infection for other bird species.

\section{MATERIALS AND METHODS}

Isolation and identification of viruses: The viruses were isolated from tracheal and cloacal swabs of wild birds. Swabs were collected in $2 \mathrm{ml}$ of transport medium containing minimum essential medium (Nissui Pharmaceutical, To- 
kyo, Japan) with $10 \mathrm{mg}$ streptomycin (Meiji Seika Pharma, Tokyo, Japan) and 10,000 units of penicillin G (Meiji Seika Pharma) and inoculated into the allantoic cavities of ten-dayold embryonated chicken eggs. After incubation at $35{ }^{\circ} \mathrm{C}$ for $48 \mathrm{hr}$, the allantoic fluids were harvested, and their HA activities were examined [16]. Subtypes of the HA and neuraminidase (NA) of influenza virus isolates were identified by polymerase chain reaction (PCR) and sequencing. Viral RNA was extracted from chicken embryos infected with viruses using QIAamp Viral RNA Mini kit (Qiagen, Hilden, Germany) and reverse transcribed with the Uni12 primer [6] and PrimeScript reverse transcriptase (Takara, Otsu, Japan). The full length of HA and NA gene segment was amplified by PCR with gene-specific primers as described previously [6]. Each gene segment was directly sequenced with 3,130 Genetic analyzer (Applied Biosystems, Foster City, CA, U.S.A.). The subtypes of the viruses were determined by comparing their sequences with those of reference strains.

Phylogenetic analysis: To assess the genetic relationship among H5N1 HPAIVs isolated in the 2010-11 winter in Japan, the full nucleotide sequences of HA coding region were applied for phylogenetic analysis. The sequences were aligned by BioEdit software [5]. Phylogenetic trees were constructed by the neighbor-joining method [14] using MEGA 5 software [18]. Bootstrap values were calculated from 1,000 replicates.

Virus detection in the carcasses: Five raptors that died of H5N1 HPAIV infection were provided by each municipal animal health laboratory under the permission of Agency for Cultural Affairs, Ministry of Education, Culture, Sports, Science and Technology in Japan. Autopsies were conducted in a biosafety level 3 facility at Avian Zoonosis Research Center, Tottori University, Japan. Each tissue was aseptically collected and homogenized to make $10 \%(\mathrm{w} / \mathrm{v})$ suspensions in nutrient broth medium with $10 \mathrm{mg}$ streptomycin and 10,000 units of penicillin $\mathrm{G}$ and inoculated into the allantoic cavities of ten-day-old embryonated chicken eggs. The infectious viral titers in the collected samples were determined in ten-day-old embryonated chicken eggs by the method of Reed and Muench [13].

\section{RESULTS}

Virus isolation from wild birds: Sixty-three H5N1 HPAIVs were isolated from wild birds, and 24 H5N1 HPAIVs were isolated from chickens during 2010-11 outbreaks in Japan $[15,21]$. Of these, 42 viruses were isolated at Tottori University from 12 species of dead wild birds from December 2010 to March 2011 (Table 1). The 12 species were Tundra swan (Cygnus columbianus), Hooded crane (Grus monacha), Common pochard (Aythya ferina), Tufted duck (Aythya fuligula), Black headed gull (Chroicocephalus ridibundus), Little grebe (Tachybaptus ruficollis), Mandarin duck (Aix galericulata), Peregrine falcon (Falco peregrinus), Ural owl (Strix uralensis), Mute swan (Cygnus olor), Grey heron (Ardea cinerea) and Great crested grebe (Podiceps cristatus).

Phylogenetic analysis of the HAs of the isolates: A phylogenetic tree of the HAs of all the isolates from wild birds and chickens in Japan and Korea in 2010-11 winter [8, 21] is shown in Fig. 1. Group A consisted of 15 isolates from Anseriformes in Fukushima and Hokkaido prefectures (Fig. 1a). The viruses isolated from resident birds and chickens were not included in this group. The viruses isolated at Tottori University shown in Table 1 were classified into Groups $\mathrm{B}$ and C (Fig. 1a and 1b). Group B contained three isolates from raptors in addition to 14 isolates from waterfowl. Group $\mathrm{C}$ included the other 33 isolates in Japan (Fig. 1b). The HAs of the viruses isolated in Korea also belonged to this group. In Group C, several characteristic subgroups were observed: Subgroup C-1 consisted of the viruses isolated in Miyazaki and Oita prefectures, located in east area of Kyusyu region of Japan (see Fig. 2); Subgroups C-5 and C-6 were composed of the strains isolated in Kagoshima and Miyazaki prefectures, respectively; Subgroups C-2, C-3 and C-4 contained the viruses which were isolated in the south-middle area of Korea [9] in addition to those in Yamaguchi prefecture and the Kyusyu region of Japan.

Epidemiology: The locations and times of HPAI outbreaks in wild birds and chickens are shown in Fig. 2. Throughout the outbreaks, the viruses in Group A were isolated in limited areas of Hokkaido and Fukushima prefecture in northern Japan. The viruses in Group B were isolated in the mid-west area of Japan; the viruses were mainly perpetuated during outbreaks in the San-in area consisting of Tottori and Shimane prefectures, and the south part of Hyogo prefecture. The viruses in Group $\mathrm{C}$ were first found in fecal samples of ducks at Ohnuma lake, Hokkaido [7]. Then, the viruses were isolated from wild birds and chickens predominantly in the Kyusyu region until March, 2011. The outbreaks were frequent in Miyazaki and Oita prefectures, located at the east side of the Kyusyu region. In the late phase of the outbreaks, the viruses in Group $\mathrm{C}$ were isolated in the south and mideast parts of the Honsyu region (e.g., Wakayama and Tochigi prefectures, respectively).

Virus recovery from birds that died of H5N1 HPAIV infection: Many viruses were isolated from raptors, such as peregrine falcon and northern goshawk (Table 1 and Fig. 1), while the populations of these bird species were smaller than those of water birds. Viruses were recovered from the systemic tissues of raptors (Table 2). In particular, viruses were detected in brain, lung, colon and cloaca of all raptors, and the viral titers in brain were highest among the tested tissues.

\section{DISCUSSION}

In the present study, all H5N1 HPAIVs isolated in Japan in the 2010-11 outbreaks were phylogenetically and epidemiologically analyzed. The viruses in Groups B and C had been mainly isolated in western Japan until March in 2011, the end of winter (Table 1 and Fig. 2). Western Japan is known as an overwintering area for migrating water birds flying from their nesting lakes in Siberia. Migrating and resident birds share living territories during winter in these areas, which explains the reason why resident birds, such as raptors and mandarin ducks with $\mathrm{H} 5 \mathrm{~N} 1$ viruses in Groups $\mathrm{B}$ and $\mathrm{C}$ were found in addition to infected migratory birds 
Table 1. The list of H5N1 HPAIVs isolated in the definitive diagnosis at Tottori University

\begin{tabular}{|c|c|c|c|c|c|}
\hline \multirow{2}{*}{$\begin{array}{l}\text { Sampling } \\
\text { day }\end{array}$} & \multirow[b]{2}{*}{ Bird species } & \multirow[b]{2}{*}{ City, Prefecture } & \multirow[b]{2}{*}{ Strain name of the isolate } & \multicolumn{2}{|c|}{ HA gene } \\
\hline & & & & $\begin{array}{c}\text { Accession } \\
\text { number }\end{array}$ & Group \\
\hline \multicolumn{6}{|c|}{ December, 2010} \\
\hline 4th & Tundra swan & Yonago, Tottori & Tundra swan/Tottori/12-002/2010 (H5N1) ${ }^{\mathrm{b})}$ & AB677923 & $\mathrm{C}$ \\
\hline 15 th & Hooded crane & Izumi, Kagoshima & Hooded crane/Kagoshima/1/2010 (H5N1) & AB760239 & $\mathrm{C}$ \\
\hline 18th & Hooded crane & Izumi, Kagoshima & Hooded crane/Kagoshima/2/2010 (H5N1) & AB760247 & $\mathrm{C}$ \\
\hline \multirow[t]{2}{*}{ 20th } & Hooded crane & Izumi, Kagoshima & Hooded crane/Kagoshima/4612J001/2010 (H5N1) & AB760255 & $\mathrm{C}$ \\
\hline & Hooded crane & Izumi, Kagoshima & Hooded crane/Kagoshima/4612J003/2010 (H5N1) & AB760263 & $\mathrm{C}$ \\
\hline 21th & Hooded crane & Izumi, Kagoshima & Hooded crane/Kagoshima/4612J004/2010 (H5N1) & $\mathrm{AB} 760271$ & $\mathrm{C}$ \\
\hline 24th & Hooded crane & Izumi, Kagoshima & Hooded crane/Kagoshima/4612J008/2010 (H5N1) ${ }^{\mathrm{b})}$ & AB677931 & $\mathrm{C}$ \\
\hline \multicolumn{6}{|c|}{ January, 2011} \\
\hline 12th & Common pochard & Itami, Hyogo & Common pochard/Hyogo/2801B004/2011 (H5N1) & AB747123 & $\mathrm{B}$ \\
\hline 14th & Tufted duck & Matsue, Shimane & Tufted duck/Shimane/5501A008/2011 (H5N1) & AB747164 & $\mathrm{B}$ \\
\hline 19th & Black headed gull & Yonago, Tottori & Black headed gull/Tottori/1-009/2011 (H5N1) & AB747167 & $\mathrm{B}$ \\
\hline 24th & Tufted duck & Yonago, Tottori & Tufted duck/Tottori/1-012/2011 (H5N1) & AB747169 & $\mathrm{B}$ \\
\hline 25 th & Little grebe & Itami, Hyogo & Little grebe/Hyogo/2801B015/2011 (H5N1) & AB747127 & $\mathrm{B}$ \\
\hline 26th & Mandarin duck & Niyodogawa, Kochi & Mandarin duck/Kochi/3901C005/2011 (H5N1) ${ }^{\text {b) }}$ & AB677891 & $\mathrm{C}$ \\
\hline \multirow[t]{2}{*}{ 31st } & Mandarin duck & Nagasaki, Nagasaki & Mandarin duck/Nagasaki/4201A011/2011 (H5N1) & $\mathrm{AB} 747105$ & $\mathrm{C}$ \\
\hline & Mandarin duck & Nagasaki, Nagasaki & Mandarin duck/Nagasaki/4202A012/2011 (H5N1) & AB747107 & $\mathrm{C}$ \\
\hline \multicolumn{6}{|c|}{ February, 2011} \\
\hline \multirow[t]{3}{*}{1 st } & Mandarin duck & Nobeoka, Miyazaki & Mandarin duck/Miyazaki/22M686/2011 (H5N1) & AB747131 & $\mathrm{C}$ \\
\hline & Tufted duck & Daisen, Tottori & Tufted duck/Tottori/3102S004/2011 (H5N1) & AB747111 & B \\
\hline & Tufted duck & Matsue, Shimane & Tufted duck/Shimane/5502B018/2011 (H5N1) & AB747171 & B \\
\hline 2nd & Peregrine falcon a) & Saito, Miyazaki & Peregrine falcon/Miyazaki/22M684/2011 (H5N1) & AB747135 & $\mathrm{C}$ \\
\hline 3rd & Common pochard & Yonago, Tottori & Common pochard/Tottori/3102S012/2011 (H5N1) & AB747114 & B \\
\hline 4th & Mandarin duck & Nagasaki, Nagasaki & Mandarin duck/Nagasaki/4202A023/2011 (H5N1) ${ }^{\text {b) }}$ & AB677867 & $\mathrm{C}$ \\
\hline \multirow[t]{2}{*}{ 6th } & Tufted duck & Ube, Yamaguchi & Tufted duck/Yamaguchi/3502B007/2011 (H5N1) & $\mathrm{AB} 677851$ & $\mathrm{C}$ \\
\hline & Peregrine falcon a) & Yonago, Tottori & Peregrine falcon/Tottori/3102S019/2011 (H5N1) & AB747117 & $\mathrm{B}$ \\
\hline 7th & Mandarin duck & Nakatsu, Oita & Mandarin duck/Oita/4402F038/2011 (H5N1) & AB747138 & $\mathrm{C}$ \\
\hline \multirow[t]{5}{*}{ 8th } & Mandarin duck & Nakatsu, Oita & Mandarin duck/Oita/4402F041/2011 (H5N1) & AB747141 & $\mathrm{C}$ \\
\hline & Mandarin duck & Nakatsu, Oita & Mandarin duck/Oita/4402F042/2011 (H5N1) & AB747144 & $\mathrm{C}$ \\
\hline & Ural owl & Naga, Tokushima & Owl/Tokushima/3602A023/2011 (H5N1) ${ }^{\mathrm{b})}$ & AB 677883 & $\mathrm{~B}$ \\
\hline & Little grebe & Morotsuka, Miyazaki & Little grebe/Miyazaki/22M718/2011 (H5N1) & AB747147 & $\mathrm{C}$ \\
\hline & Common pochard & Matsue, Shimane & Common pochard/Shimane/5502B024/2011 (H5N1) ${ }^{\mathrm{b})}$ & AB677843 & $\mathrm{B}$ \\
\hline \multirow[t]{2}{*}{ 9th } & Mandarin duck & Oita, Oita & Mandarin duck/Oita/4402B056/2011 (H5N1) & AB677859 & $\mathrm{C}$ \\
\hline & Tufted duck & Izumo, Shimane & Tufted duck/Shimane/3202C002/2011 (H5N1) & AB747173 & $\mathrm{B}$ \\
\hline \multirow[t]{2}{*}{ 11th } & Mute swan & Kato, Hyogo & Mute swan/Hyogo/2802F001/2011 (H5N1) & AB747109 & $\mathrm{B}$ \\
\hline & Peregrine falcon & Miyazaki, Miyazaki & Peregrine falcon/Miyazaki/22M754/2011 (H5N1) & $\mathrm{AB} 747150$ & $\mathrm{C}$ \\
\hline 12th & Peregrine falcon & Isahaya, Nagasaki & Peregrine falcon/Nagasaki/4202A039/2011 (H5N1) & $\mathrm{AB} 747153$ & $\mathrm{C}$ \\
\hline 13th & Hooded crane & Izumi, Kagoshima & Hooded crane/Kagoshima/110214-3/2011 (H5N1) & AB760279 & $\mathrm{C}$ \\
\hline 14th & Mandarin duck & Nichinan, Miyazaki & Mandarin duck/Miyazaki/22M765/2011 (H5N1) & $\mathrm{AB} 747155$ & $\mathrm{C}$ \\
\hline \multirow[t]{2}{*}{15 th } & Grey heron & Oita, Oita & Grey heron/Oita/4402B069/2011 (H5N1) & AB747159 & $\mathrm{C}$ \\
\hline & Peregrine falcon a) & Nobeoka, Miyazaki & Peregrine falcon/Miyazaki/22M771/2011 (H5N1) & $\mathrm{AB} 747161$ & $\mathrm{C}$ \\
\hline 16th & Peregrine falcon & Seika, Kyoto & Peregrine falcon/Kyoto/2602A009/2011 (H5N1) ${ }^{\mathrm{b})}$ & AB677907 & $\mathrm{B}$ \\
\hline 17 th & Peregrine falcon a) & Kasugai, Aichi & Peregrine falcon/Aichi/2302O017/2011 (H5N1) ${ }^{\mathrm{b}}$ ) & AB677915 & $\mathrm{C}$ \\
\hline 18th & Mandarin duck & Miyazaki, Miyazaki & Mandarin duck/Miyazaki/22M807-1/2011 (H5N1) ${ }^{\mathrm{b})}$ & $\mathrm{AB} 677875$ & $\mathrm{C}$ \\
\hline 22nd & Great crested grebe & Nishinomiya, Hyogo & Great crested grebe/Hyogo/2802E082/2011 (H5N1) ${ }^{\mathrm{b})}$ & AB677899 & B \\
\hline \multicolumn{6}{|c|}{ March, 2011} \\
\hline 6th & Tufted duck & Matsue, Shimane & Tufted duck/Shimane/3203A004/2011 (H5N1) & AB747119 & B \\
\hline
\end{tabular}

a) These birds were applied for autopsy in this study. b) Sakoda et al. [15].

(Fig. 1). Moreover, HPAI outbreaks in poultry were dominantly observed in the western area. Resident birds might play a role as intermediate hosts between chicken populations and water birds. In early spring, the late phase of out- breaks, the viruses in Group C were isolated in the Honsyu region (Fig. 2). The spreading of the Group $C$ viruses might be due to migrating or wandering birds that are returning to northern breeding sites. 


\section{a}

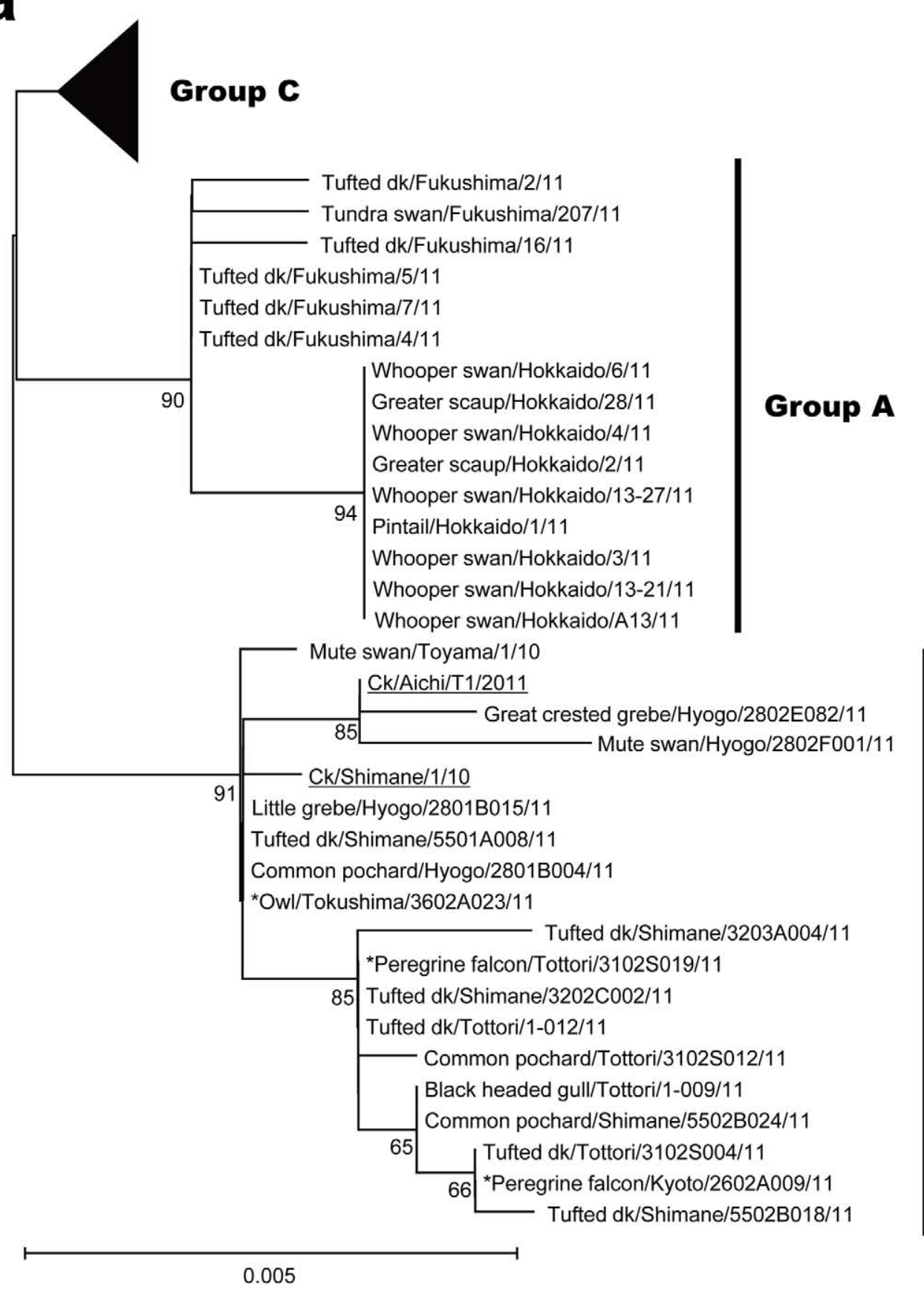

Group B

Fig. 1. Phylogenetic trees of the HA genes of H5N1 HPAIV isolated in 2010-11 winter in Japan and Korea. The isolates were divided into three (A-C) groups. (a) Groups A-B; (b) Group C. The full protein coding regions of H5 HA genes were used for the analysis. Horizontal distances are proportional to the minimum number of nucleotide differences required to join nodes and sequences. Numbers at the nodes indicate confidence levels in a bootstrap analysis with 1,000 replications. Bootstrap values of more than 60 are shown at each branch. The host and year in strain names were abbreviated as follows: chicken; Ck, duck; $\mathrm{Dk}, 2011 ; 11$. The viruses isolated from domestic poultry are underlined. The strains isolated from birds of prey are denoted by an asterisk. Blue indicates the viruses isolated in Korea. Of these, isolates in south-middle region were additively in italic with boldface [8, 9]. 


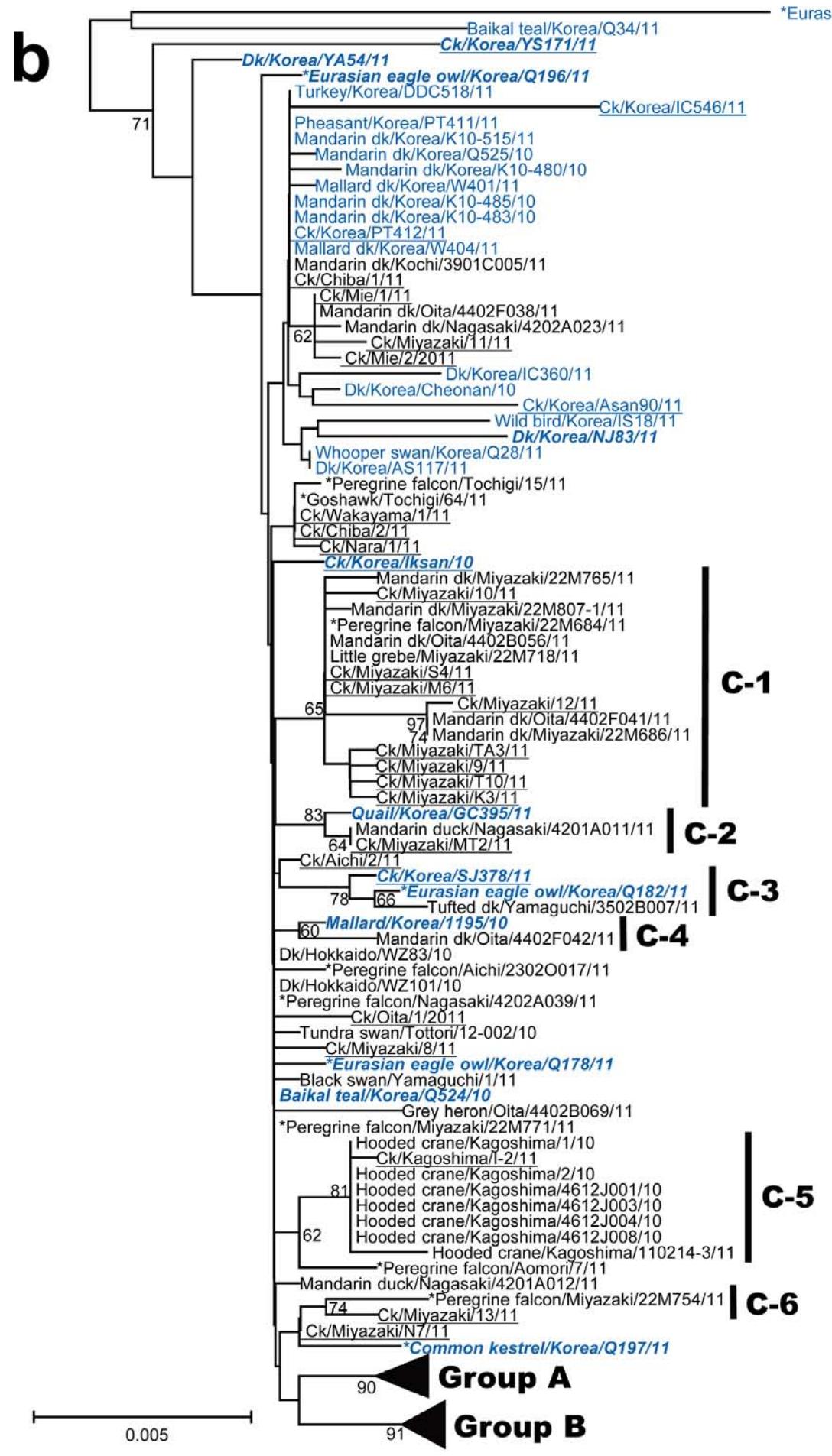


O Wild Birds

$\Delta$ Chickens

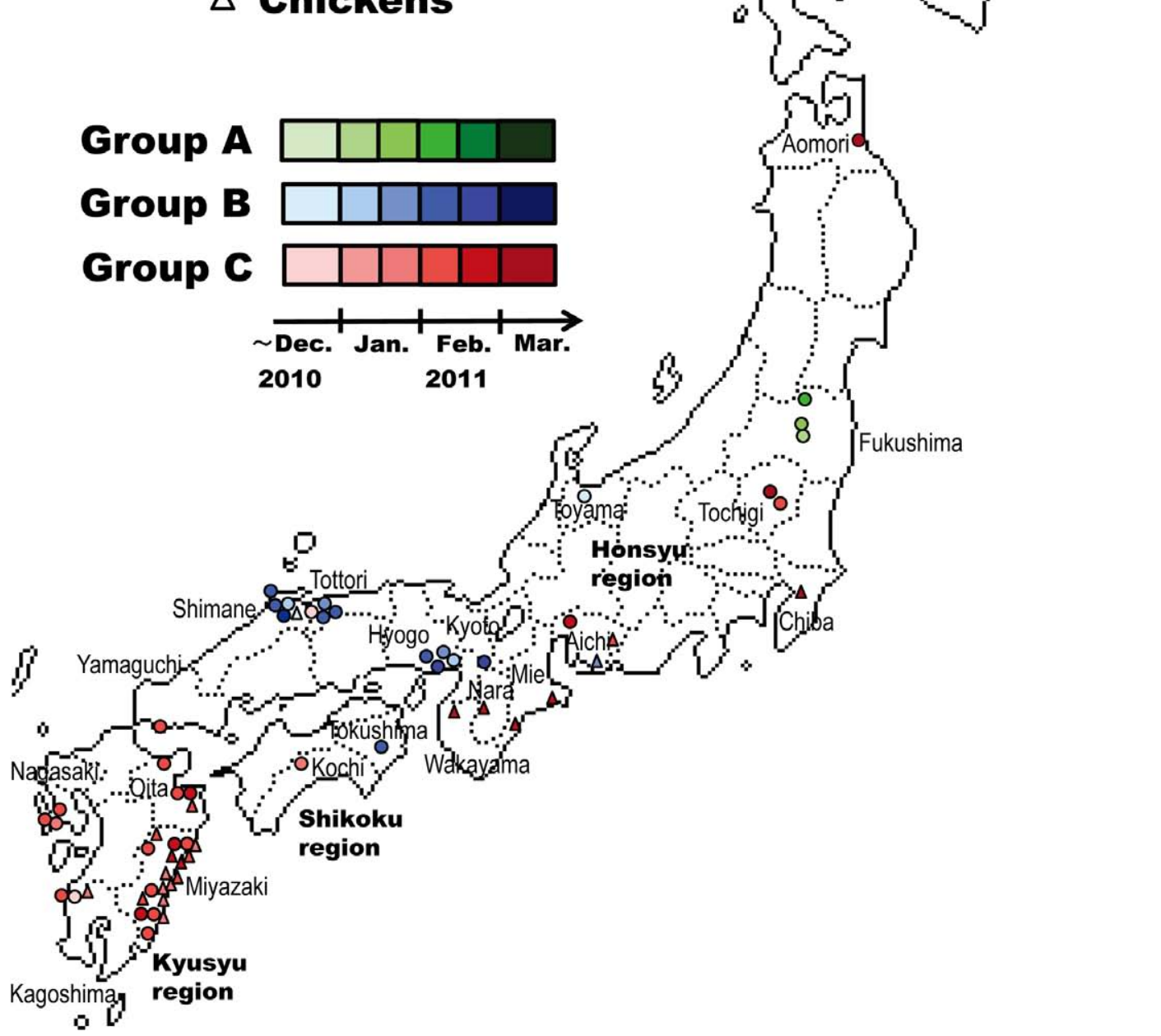

Fig. 2. Map of H5N1 virus infection in wild birds (circles) and chickens (triangles) in the 2010-11 winter in Japan. The times of HPAI outbreaks were divided into 6 separate terms, represented by the different colors. Subsequent cases at the same places and in the same period are omitted.

H5N1 HPAIVs isolated in Korea around the same period [9] were classified into Group C (Fig. 1b). Kim et al. reported that virus isolates from poultry in Korea fell into two sublineages, south-middle and north-middle, which were distinct geographic regions in the HPAI outbreaks in poultry, but the isolates from wild birds were not subgrouped in the phylogenetic tree, which displays only topology [9]. Interestingly, some Korean viruses isolated in the southmiddle region and some viruses in Yamaguchi prefecture and the Kyusyu region of Japan were classified into the same subgroups in the present study (C-2, C-3 and C-4 in
Fig. 1b). Because these regions are geographically close to each other, migratory birds were suspected of contributing to the transportation of the viruses across the sea. On the other hand, all the viruses in Subgroups C- 1 and C- 6 were isolated only in the Kyusyu region (Fig. 1b), indicating that these viruses were maintained in local bird populations during the outbreak periods. Moreover, the viruses in these subgroups were isolated from poultry in addition to resident birds, suggesting that direct or indirect viral transmission among them occurred in each prefecture.

All the isolates from hooded cranes at the Izumi migra- 
Table 2. Viral titers recovered from the tissues of the raptors died of H5N1 HPAIV infection

\begin{tabular}{|c|c|c|c|c|c|}
\hline \multirow{3}{*}{ Samples } & \multicolumn{4}{|c|}{ Peregrine falcons } & \multirow{3}{*}{$\begin{array}{c}\text { Northern goshawk } \\
\text { Tochigi } \\
64\end{array}$} \\
\hline & Miyazaki & Shimane & Miyazaki & Aichi & \\
\hline & $22 \mathrm{M} 684$ & 3102S019 & 22M771 & $2302 \mathrm{O} 017$ & \\
\hline \multicolumn{6}{|l|}{ Organs } \\
\hline Brain & 5.7 & 7.5 & 5.7 & 5.5 & 4.7 \\
\hline Trachea & - a) & 5.3 & - & 3.7 & 2.5 \\
\hline Lung & 3.7 & 3.7 & 4.3 & 4.3 & 4.3 \\
\hline Liver & - & 4.5 & - & 2.5 & - \\
\hline Pancreas & - & - & 3.3 & $\leq 2.0$ & 3.3 \\
\hline Spleen & - & - & - & $\leq 2.0$ & - \\
\hline Heart & - & 2.5 & - & 2.7 & - \\
\hline Kidney & - & 3.3 & 2.7 & 5.3 & - \\
\hline \multicolumn{6}{|l|}{ Locomotorium } \\
\hline Breast muscle & - & 2.5 & - & - & - \\
\hline \multicolumn{6}{|c|}{ Digestive organs } \\
\hline Esophagus & - & 4.7 & 2.5 & 3.7 & $\leq 2.0$ \\
\hline Avian crop & - & 4.5 & - & 3.7 & - \\
\hline Proventriculus & - & 2.3 & - & 3.5 & $\leq 2.0$ \\
\hline Gizzard & - & 2.7 & - & 2.5 & $\leq 2.0$ \\
\hline Duodenum & - & - & - & 2.5 & $\leq 2.0$ \\
\hline Jejunum-ileum & - & - & - & 4.5 & - \\
\hline Colon & 2.5 & 4.5 & 4.5 & 4.5 & $\leq 2.0$ \\
\hline Cloaca & 2.7 & 4.3 & 3.3 & 4.5 & 3.3 \\
\hline
\end{tabular}

a) $\leq 1.5$.

tion grounds in Kagoshima prefecture were classified into Subgroup C-5. The viruses were isolated in December 2010 and February 2011 (Table 1). These results suggest that the viruses were present in the crane populations for 2 months. Hooded crane is evaluated as Vulnerable on the IUCN (International Union for Conservation of Nature) Red List of Threatened Species. Of a total population of about 10,000 birds, $90 \%$ live at high densities and overwinter at the Izumi crane migration grounds. In the HPAI outbreaks in 2010-11, H5N1 HPAIV infection was confirmed in only seven cranes (Table 1), suggesting that the pathogenicity of circulating HPAIV to these birds was low. To protect cranes from H5N1 HPAIV infection in the future, the number of overwintering cranes and the antibody prevalence in these birds should be continuously monitored.

In the outbreaks in Japan, quite a few raptors died of HPAIV infection [15]. H5N1 HPAIVs were also reported to be lethal to other raptor species such as American Kestrel (Falco sparverius) [4], Crested Hawk-eagle (Nisaetus cirrhatus) [22], Eurasian Sparrowhawk (Accipiter nisus) [3], Gyrfalcon-Saker hybrids (Falco rusticolus x Falco cherrug) [1] and Saker Falcon (Falco cherrug) [10]. Gyrfalcon-Saker hybrids can also be infected by feeding on infected prey [1]. Furthermore, viruses were recovered from digestive organs of some raptors dissected in this study (Table 2). Together, these results suggest that raptors were infected with HPAIV by their predatory behavior, eating infected birds or carrion in the environment. Since viruses were disseminated to systemic tissues of the dissected raptors (Table 2), they were a potential source of infection to other scavengers.

The past HPAI outbreaks in Japan were successfully con- trolled by stamping out measures without the use of vaccine. As of December 2012, no outbreak had been reported since March 2011. HPAIV should be contained in domestic poultry population and eradicated by proper countermeasures as described previously [15], and this should help to protect wild fowls including rare species from HPAIV infection. Moreover, it is important that all diagnosis institutes rapidly report information about outbreaks and causal viruses to the public in order to take preemptive measures against further HPAI occurrences.

ACKNOWLEDGMENTS. We deeply appreciate the kind cooperation of the Ministry of Environment and Ministry of Agriculture, Forestry and Fisheries, Government of Japan. We thank municipal animal health laboratory for providing the bird cadavers infected with H5N1 HPAIV. Registration of the sequence data to DNA Data Bank of Japan (DDBJ) was supported by W. Mimura and Y. Hashimoto, technical assistants in Tottori University. This study was supported by the program of Strategic Fund for Promotion of Science and Technology of the Ministry of Education, Culture, Sports, Science and Technology.

\section{REFERENCES}

1. Bertran, K., Busquets, N., Abad, F. X., Garcia De La Fuente, J., Solanes, D., Cordon, I., Costa, T., Dolz, R. and Majo, N. 2012. Highly (H5N1) and low (H7N2) pathogenic avian influenza virus infection in falcons via nasochoanal route and ingestion of experimentally infected prey. PLoS ONE 7: e32107. [Medline] [CrossRef] 
2. Chen, H., Smith, G. J., Zhang, S. Y., Qin, K., Wang, J., Li, K. S., Webster, R. G., Peiris, J. S. and Guan, Y. 2005. Avian flu: H5N1 virus outbreak in migratory waterfowl. Nature 436: 191-192. [Medline] [CrossRef]

3. Couacy-Hymann, E., Danho, T., Keita, D., Bodjo, S. C., Kouakou, C., Koffi, Y. M., Beudje, F., Tripodi, A., De Benedictis, P. and Cattoli, G. 2009. The first specific detection of a highly pathogenic avian influenza virus (H5N1) in Ivory Coast. Zoonoses Public Health 56: 10-15. [Medline] [CrossRef]

4. Hall, J. S., Ip, H. S., Franson, J. C., Meteyer, C., Nashold, S., Teslaa, J. L., French, J., Redig, P. and Brand, C. 2009. Experimental infection of a North American raptor, American Kestrel (Falco sparverius), with highly pathogenic avian influenza virus (H5N1). PLoS ONE 4: e7555. [Medline] [CrossRef]

5. Hall, T. A. 1999. BioEdit: a user-friendly biological sequence alignment editor and analysis program for Windows 95/98/NT. Nucleic Acids Symposium Series No. 41: 95-98.

6. Hoffmann, E., Stech, J., Guan, Y., Webster, R. G. and Perez, D. R. 2001. Universal primer set for the full-length amplification of all influenza A viruses. Arch. Virol. 146: 2275-2289. [Medline] [CrossRef]

7. Kajihara, M., Matsuno, K., Simulundu, E., Muramatsu, M., Noyori, O., Manzoor, R., Nakayama, E., Igarashi, M., Tomabechi, D., Yoshida, R., Okamatsu, M., Sakoda, Y., Ito, K., Kida, H. and Takada, A. 2011. An H5N1 highly pathogenic avian influenza virus that invaded Japan through waterfowl migration. Jpn. J. Vet. Res. 59: 89-100. [Medline]

8. Kim, H. R., Kim, B. S., Bae, Y. C., Moon, O. K., Oem, J. K., Kang, H. M., Choi, J. G., Lee, O. S. and Lee, Y. J. 2011. H5N1 subtype highly pathogenic avian influenza virus isolated from healthy mallard captured in South Korea. Vet. Microbiol. 151: 386-389. [Medline] [CrossRef]

9. Kim, H. R., Lee, Y. J., Park, C. K., Oem, J. K., Lee, O. S., Kang, H. M., Choi, J. G. and Bae, Y. C. 2012. Highly pathogenic avian influenza (H5N1) outbreaks in wild birds and poultry, South Korea. Emerg. Infect. Dis. 18: 480-483. [Medline] [CrossRef]

10. Lierz, M., Hafez, H. M., Klopfleisch, R., Luschow, D., Prusas, C., Teifke, J. P., Rudolf, M., Grund, C., Kalthoff, D., Mettenleiter, T., Beer, M. and Hardert, T. 2007. Protection and virus shedding of falcons vaccinated against highly pathogenic avian influenza A virus (H5N1). Emerg. Infect. Dis. 13: 1667-1674. [Medline] [CrossRef]

11. Liu, J., Xiao, H., Lei, F., Zhu, Q., Qin, K., Zhang, X. W., Zhang, X. L., Zhao, D., Wang, G., Feng, Y., Ma, J., Liu, W., Wang, J. and Gao, G. F. 2005. Highly pathogenic H5N1 influenza virus infection in migratory birds. Science 309: 1206. [Medline] [CrossRef]

12. Mase, M., Tsukamoto, K., Imada, T., Imai, K., Tanimura, N., Nakamura, K., Yamamoto, Y., Hitomi, T., Kira, T., Nakai, T., Kiso, M., Horimoto, T., Kawaoka, Y. and Yamaguchi, S. 2005.
Characterization of $\mathrm{H} 5 \mathrm{~N} 1$ influenza A viruses isolated during the 2003-2004 influenza outbreaks in Japan. Virology 332: 167-176. [Medline] [CrossRef]

13. Reed, M. and Muench, H. 1938. A simple method for estimating fifty percent endpoints. Am. J. Hyg. 37: 493-497.

14. Saitou, N. and Nei, M. 1987. The neighbor-joining method: a new method for reconstructing phylogenetic trees. Mol. Biol. Evol. 4: 406-425. [Medline]

15. Sakoda, Y., Ito, H., Uchida, Y., Okamatsu, M., Yamamoto, N., Soda, K., Nomura, N., Kuribayashi, S., Shichinohe, S., Sunden, Y., Umemura, T., Usui, T., Ozaki, H., Yamaguchi, T., Murase, T., Ito, T., Saito, T., Takada, A. and Kida, H. 2012. Reintroduction of $\mathrm{H} 5 \mathrm{~N} 1$ highly pathogenic avian influenza virus by migratory water birds, causing poultry outbreaks in the 2010-2011 winter season in Japan. J. Gen. Virol. 93: 541-550. [Medline] [CrossRef]

16. Sever, J. L. 1962. Application of a microtechnique to viral serological investigations. J. Immunol. 88: 320-329. [Medline]

17. Shivakoti, S., Ito, H., Otsuki, K. and Ito, T. 2010. Characterization of $\mathrm{H} 5 \mathrm{~N} 1$ highly pathogenic avian influenza virus isolated from a mountain hawk eagle in Japan. J. Vet. Med. Sci. 72: 459-463. [Medline] [CrossRef]

18. Tamura, K., Peterson, D., Peterson, N., Stecher, G., Nei, M. and Kumar, S. 2011. MEGA5: molecular evolutionary genetics analysis using maximum likelihood, evolutionary distance, and maximum parsimony methods. Mol. Biol. Evol. 28: 2731-2739. [Medline] [CrossRef]

19. Tanimura, N., Tsukamoto, K., Okamatsu, M., Mase, M., Imada, T., Nakamura, K., Kubo, M., Yamaguchi, S., Irishio, W., Hayashi, M., Nakai, T., Yamauchi, A., Nishimura, M. and Imai, K. 2006. Pathology of fatal highly pathogenic H5N1 avian influenza virus infection in large-billed crows (Corvus macrorhynchos) during the 2004 outbreak in Japan. Vet. Pathol. 43: 500-509. [Medline] [CrossRef]

20. Uchida, Y., Mase, M., Yoneda, K., Kimura, A., Obara, T., Kumagai, S., Saito, T., Yamamoto, Y., Nakamura, K., Tsukamoto, K. and Yamaguchi, S. 2008. Highly pathogenic avian influenza virus (H5N1) isolated from whooper swans, Japan. Emerg. Infect. Dis. 14: 1427-1429. [Medline] [CrossRef]

21. Uchida, Y., Suzuki, Y., Shirakura, M., Kawaguchi, A., Nobusawa, E., Tanikawa, T., Hikono, H., Takemae, N., Mase, M., Kanehira, K., Hayashi, T., Tagawa, Y., Tashiro, M. and Saito, T. 2012. Genetics and infectivity of H5N1 highly pathogenic avian influenza viruses isolated from chickens and wild birds in Japan during 2010-11. Virus Res. 170: 109-117. [Medline] [CrossRef]

22. Van Borm, S., Thomas, I., Hanquet, G., Lambrecht, B., Boschmans, M., Dupont, G., Decaestecker, M., Snacken, R. and Van Den Berg, T. 2005. Highly pathogenic H5N1 influenza virus in smuggled Thai eagles, Belgium. Emerg. Infect. Dis. 11: 702-705. [Medline] [CrossRef] 